\title{
Design and psychometric properties of a questionnaire to assess gender sensitivity of perinatal care services: a sequential exploratory study
}

Masoumeh Simbar ${ }^{1,2}$, Fatemeh Rahmanian², Soheila Nazarpour ${ }^{3 *}$ (D, Ali Ramezankhani ${ }^{4}$, Narges Eskandari ${ }^{5}$ and Farid Zayeri $^{6}$

\begin{abstract}
Background: Providing gender sensitive reproductive health service is recently emphasized by health organizations. This study aims to develop and assess psychometric properties of a questionnaire to assess gender sensitivity of perinatal care services (GS-PNCS) to be used by managers of perinatal services.

Methods: This study is a mixed sequential (Qualitative-Quantitative) exploratory study. In the qualitative phase, 34 participants were interviewed and the items were generated. To evaluate the validity; face, content and construct validity were assessed. The reliability was assessed by internal consistency and stability calculation.

Results: The content validity and reliability were demonstrated by S-CVR $=0.92$ and S-CVI $=0.98$, Cronbach's $a=0.880$ and the ICC $=0.980$ to 0.947 . Exploratory factor analysis showed 8 factors which explained more than $52.53 \%$ of the variance.
\end{abstract}

Conclusion: GS-PNCS is a valid and reliable questionnaire, with 49 items to assess gender sensitivity of perinatal care services and helps health care managers and planners to improve the quality of the services.

Keywords: Gender, Psychometric properties, Perinatal care, Questionnaire

\section{Background}

Gender is a social construct referring to the culturally and historically based differences in the roles, attitudes and behaviors of men and women [1]. Men and women are not only different regarding their biological and hormonal conditions, vulnerability, prevalence and the incidence of diseases, but also respecting their health behaviors and experiences about diseases [2]. Besides, the social and

\footnotetext{
* Correspondence: soheilanazarpour@iauc.ac.ir; sn_9547@yahoo.com ${ }^{3}$ Department of Midwifery, Chalous Branch, Islamic Azad University, 17 Shahrivar Street, opposite the mosque of Imam Hussain (AS), Chalous 4661961367, Iran

Full list of author information is available at the end of the article
}

economic status affect the responses of men and women to the diseases [3].

Gender sensitivity of health care services is fundamental for quality of care services and mentioned as a Global Strategy for Women's Health [4]. It means that medical personnel understand gender health needs differences and use them in their decision making and activities in preventive and curative process [5]. The health care providers should consider the effects of biological factors of the individuals as well as clients' position of life, position in the community and the social beliefs about femininity and masculinity [6-8].

Providing gender appropriate reproductive services are necessary because gender differences are effective on

C C The Author(s). 2020 Open Access This article is licensed under a Creative Commons Attribution 4.0 International License, which permits use, sharing, adaptation, distribution and reproduction in any medium or format, as long as you give appropriate credit to the original author(s) and the source, provide a link to the Creative Commons licence, and indicate if changes were made. The images or other third party material in this article are included in the article's Creative Commons licence, unless indicated otherwise in a credit line to the material. If material is not included in the article's Creative Commons licence and your intended use is not permitted by statutory regulation or exceeds the permitted use, you will need to obtain permission directly from the copyright holder. To view a copy of this licence, visit http://creativecommons.org/licenses/by/4.0/. The Creative Commons Public Domain Dedication waiver (http://creativecommons.org/publicdomain/zero/1.0/) applies to the data made available in this article, unless otherwise stated in a credit line to the data. 
individuals' reproductive health, especially on maternal health, contraceptive use, the prevention of high-risk sexual relationships, and the transmission of STIs [6]. Gender is one of the most important factors that must be taken into account when deciding about management and providing reproductive health care services [9].

Prenatal Care services (PNCS) are important programs in reproductive health, which aim to provide quality care and counseling for mothers to achieve women's empowerment and rights [10]. However, the focus on women and the tendency to think that pregnancy, childbirth, child health and family planning are woman's job caused men to be excluded from these services. While access to health services is one of the fundamental rights of both, men and women [11].

Development of indicators and tools to assess gender sensitivity of reproductive health including PNCS are essential for monitoring and evaluating of the services and improving the quality of care. Gender sensitive health policies and programs require a thorough analysis of needs to achieve women and men health [4, 12]. Reproductive health programs are not succeed if they would not be able to identify needs for gender sensitivity in their policies and implementation, and if they would not be able to response to the needs of women and men [13]. Therefore, a valid and reliable tool is necessary for health policy makers and managers to recognize gender sensitivity of reproductive health care and overcome the barriers and meet the needs to achieve quality reproductive health care services.

In this regard, a few tools were designed to measure gender sensitivity in STI services [14], male participation in PNCS [15] and reproductive health services [16]. The most comprehensive questionnaire to assess gender sensitivity in reproductive health services is available at the level of staff and facilities [17].

Since the causes of insensitivity of reproductive health services are complex and related to many other factors rather than health service providers and managers; such as institutional structure, values, priorities and process of providing services, the characteristics of health services and the culture of each country [17], this study aims to design a comprehensive, valid and reliable questionnaire to assess needs for providing the gender sensitive PNCS respecting all factors related to gender sensitivity of PNCS.

\section{Methods}

This study was a mixed sequential exploratory study to develop a valid and reliable questionnaire to assess gender sensitivity of perinatal care services (GS-PNCS). So, the study was performed in two qualitative and quantitative phases, using Waltz steps [18] for tool development.

\section{The qualitative phase: development of the tool Design of the study}

To generate appropriate preliminary items, an inductivedeductive approach was conduct. Firstly, a qualitative study with the content analysis approach was performed to explain the concept and dimensions of gender sensitive PNCS from the perspectives of the experts and providers. Then, a detailed related literature review was performed [19]. The items were extracted from both studies.

\section{The participants}

The participants of the study were policy makers, providers and managers of PNCS including prenatal-, child birth and postpartum care services. The participants had at least 2 years of experience in PNCs and interest to participate in the study.

\section{Sampling}

Sampling was started purposive and continued with a snowball sampling method. It was performed with the maximum diversity in gender, work experience and education. Finally, 34 policy makers, managers and service providers in PNCs participated in the study.

\section{Setting}

All public and private clinics and hospitals in Shiraz and the headquarters of PNCS of Ministry of Health in Tehran were selected as the research environment.

\section{Tool of the study}

The guide questions for the interview and data collection were: What is the concept of "gender sensitive PNCs?; What is your understanding and experience of the specific cultural, social and religious conditions that lead to the creation of different needs of women and men in PNCs?; What are the specific educational needs of the providers for a gender based counseling and care?

\section{Procedure of the study}

Data was collected using a deep face to face individual interview by using the semi-structured interviews and continued until data saturation, when no new code of data was added to the study. The interviews were conducted by second author, Dr. Rahmanian who is $\mathrm{PhD}$ in Reproductive Health, and an assistant professor in the Department of Midwifery and Reproductive Health at Shiraz University of Medical Sciences. She has more than 15 years' work experiences in perinatal care services as a midwife, trainer and manager. After introducing the interviewer, the participants were informed about goals of the study and confidentiality of their personal information. Also, field notes were made during and after interview. The interviews were performed after two pilot interviews. The average duration of interviews was 60 to 
90 min. All interviews were audio recorded, transcribed, typed and coded on the same day. The transcripts were returned to participants for comments and corrections.

\section{Data analysis}

The collected data was analyzed using qualitative conventional content analysis approach based on the Graneheim and Lundman's method [20]. MAXQDA v.10 was used for data management.

\section{Data trustworthiness}

Lincoln and Guba's [21] criteria was considered to evaluate trustworthiness, through assessing credibility, transferability, conformability, and dependability of the qualitative data. The codded data were checked by participants, peers and the experts and their feedback were considered.

\section{The review process}

Then an extensive review of literature was performed using key words include: "scale", "tool", "instrument", "check list", "questionnaire", "gender", "maternity", "perinatal", through databases, PubMed, Google Scholar, Science Direct, Scopus, and World Health Organization. Findings of this part did not add any items.

\section{GS-PNCS development}

\section{Item generation}

The first extracted items were generated from qualitative part of the study (72 items). The review of literature did not add any items to the preliminary questionnaire.

\section{Scoring}

The scale was scored based on a 3-point Likert scale, scoring 1 to 3 for "not at all", "a little" and "much" options, respectively.

\section{Quantitative part: psychometric assessment of GS- PNCS}

In the quantitative part, the psychometric properties of the questionnaire including; quantitative and qualitative face validity, quantitative and qualitative content validity, construct validity and reliability of the tool were assessed.

\section{Face validity assessment}

For qualitative assessment of face validity, the preliminary questionnaire was evaluated by 15 perinatal care providers and managers including; 2 reproductive health specialists, 3 perinatal service managers and 8 midwives, and 2 health experts. These participants assessed difficulty, generality and ambiguity of the items. The items impact scores were calculated to assess the face validity quantitatively. At this stage, the above mentioned participants rated each item by the 5 -point Likert scale from completely important to not at all important, scoring 5 to 1 . To calculate the item impact score, the following formula was applied: Item impact score $=$ Frequency $($ percentage $) \times$ Importance. The items with an impact score of more than 1.5 were appropriate and maintained for later stages [22].

\section{Content validity assessment}

Content validity of the questionnaire was examined qualitatively and quantitatively. In the qualitative content validity assessment, 10 experts in reproductive health and midwives were asked to comment on the items regarding the grammar of items, choice of vocabulary, placement of items, and scoring [23]. In quantitative content validity assessment, content validity ratio (CVR) and content validity index (CVI) were calculated.

The content validity ratio was assessed by 13 experts. The participants scored the items based on a 3-point Likert scale (essential, useful but not essential, not essential).

CVR was calculated through the following formula

$$
C V R=\frac{n_{E}-(N / 2)}{N / 2}
$$

where $n_{E}$ stands for the number of specialists who have chosen the option "essential" and $N$ is the total number of specialists. According to Lawshe's table [24], the CVR higher than 0.54 for 13 individuals indicate the necessity of the item at a statistically significant level $(P=0.05)$.

Content Validity Index (CVI) was assessed by the same 13 experts who scored items of the questionnaire based on their "simplicity", "relevance" and "clarity" using the 4-level Likert scale (scores 0 to 3 for "not at all" to "completely") based on Waltz \& Bausell's content validity index [25].

CVI was calculated according to the following formula:

$$
\mathrm{CVI}=\frac{\text { Number of raters chosing points } 3 \text { and } 4}{\text { Total number of raters }}
$$

Items with a CVI higher than 0.79 , between 0.70 and 0.79 , and lower than 0.70 were considered suitable, needing modification, and unacceptable, respectively [23]. The scale's content validity ratio (S-CVR) and the scale's content validity index (S-CVI) were obtained through calculating of mean of items' CVR and CVI.

\section{Construct validity assessment \\ Design of the study}

Construct validity of GS-PNCS was evaluated through exploratory factor analysis (EFA) through a cross sectional study.

\section{Subjects of the study}

285 PNCs' providers including prenatal, child birth and postpartum care providers, with at least 2 years of care or management experience, and willingness to participate were recruited. 


\section{Sampling}

The number of samples in this study was determined 5 samples for each item of the designed questionnaire. Plichta et al. (2013) states that the required number of responders for EFA is between 3 and 10 persons per item, or a total of 100 to 200 responders [26]. Therefore, all 285 perinatal care providers of health centers and hospitals affiliated to Shiraz University of Medical Sciences in Iran, who had the inclusion criteria of the study recruited for the study using convenience method of sampling.

\section{Setting}

The subjects of the study were recruited from all 37 health centers and all 9 public and private hospitals in Shiraz.

\section{Tool for data collection}

Tool for data collection was GS-PNCS following face and content validity assessment.

\section{Data analysis}

To confirm the adequacy of the sample size for EFA, two criteria of Kaiser-Meyer-Alekin (KMO) and Bartlett
Sphericity Test were measured. Adequacy of the sample size for EFA could be shown while the calculated KMO index is more than 0.8 and the $p$ value of the Bartlett Sphericity test is less than 0.05 [26].

Then, the items were examined regarding suitability to enter factor analysis by calculating of commonalities. Next, items with commonalities of higher than 0.4 were selected for the analysis.

Quartimax rotation was used for factor analysis in this study. Quartimax minimizes the number of factors needed to explain each variable [27]. The factors of the tool were extracted using the Kaiser (1960) criterion, with the acceptance of factors having an Eigen value of more than one; and drawing the Screeplot.

\section{Reliability assessment}

To confirm the GS-PNCS's reliability, internal consistency was assessed through Cronbach's alpha calculation, and the questionnaire's stability was evaluated through the calculation of the correlation coefficient of the test-retest and the intraclass correlation coefficient.

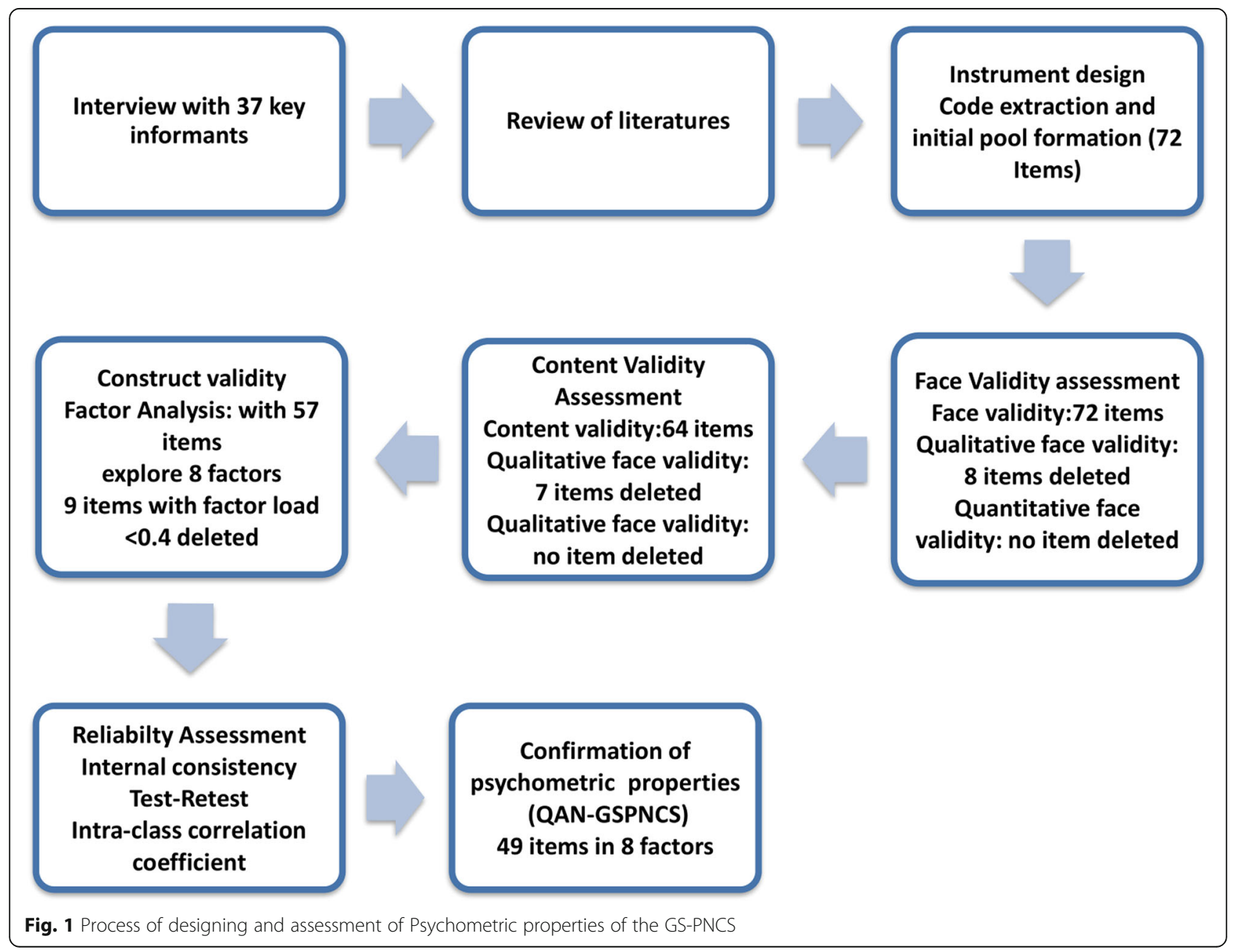




\section{The internal consistency assessment}

The internal consistency of GS-PNCS was calculated by calculating the Cronbach's alpha coefficient, and the values above 0.7 were considered acceptable $[28,29]$. To assess internal consistency, 30 eligible providers of perinatal care filled up the questionnaire

\section{Stability assessment}

Stability of GS-PNCS was assessed through the test-retest method. The questionnaires were filled up by 30 eligible providers with a 2-week interval and then Pearson correlation and intra-class correlation coefficients of scores of the two tests were calculated.

The Pearson correlation coefficient more than 0.7 [23] and ICC higher than 0.4 were considered as the acceptable levels for stability [30].

The SPSS-V.21 was used to perform all statistical analyses. A summary of steps for designing and assessment of psychometric properties of GS-PNCS is presented in Fig. 1.

\section{Results}

The Findings are presented in two parts: 1) designing of GS-PNCS; and 2) assessing the psychometric properties of the GS-PNCS.

\section{Qualitative phase: designing of the questionnaire}

In the qualitative section, 34 interviews with 34 perinatal care providers and manages were performed in their office or PNC clinics. Nobody refused or dropped out the interviews. Then an extensive review was performed on the related literature. These led to the explanation of the concept of gender sensitive PNCS. Then, using the extracted concept, the practical definitions of the dimentions of gender sensitive PNCS were extracted. Accordingly, the questionnaire of gender sensitive perinatal care services (GS-PNCS) is a tool that measures the responsiveness of PNCS to the needs of men and women based on their gender roles. The needs are in all dimensions of the services including structure of the services consisting of human resources, facilities and managers; processes of the services including care and educational procedures; supporting policies, consist of intersectoral co-operation and community empowerment.

The extracted items from the qualitative part and the literature review made the primary pool of GS-PNCS. These 72 items were classified in 8 subcategories and 3 categories/themes (Fig. 2).

\section{Quantitative phase: assessment of psychometric properties of GS-PNCS}

In the quantitative part, face-, content- and construct validity and then the reliability of GS-PNCS were examined.

\section{Face validity assessment}

In the qualitative face validity assessment, 8 items were omitted for ambiguity and generality. In the quantitative face validity assessment, the importance of each item was measured and the items with impact score of more than 1.5 were maintained. In this stage, all phrases received a score of more than 1.5 .

\section{Content validity assessment}

In the Qualitative Content validity assessment, 7 items were deleted. In quantitative content validity assessment, no item was deleted as they obtained acceptable CVI and CVR level. Finally, content validity of GS-PNCS was

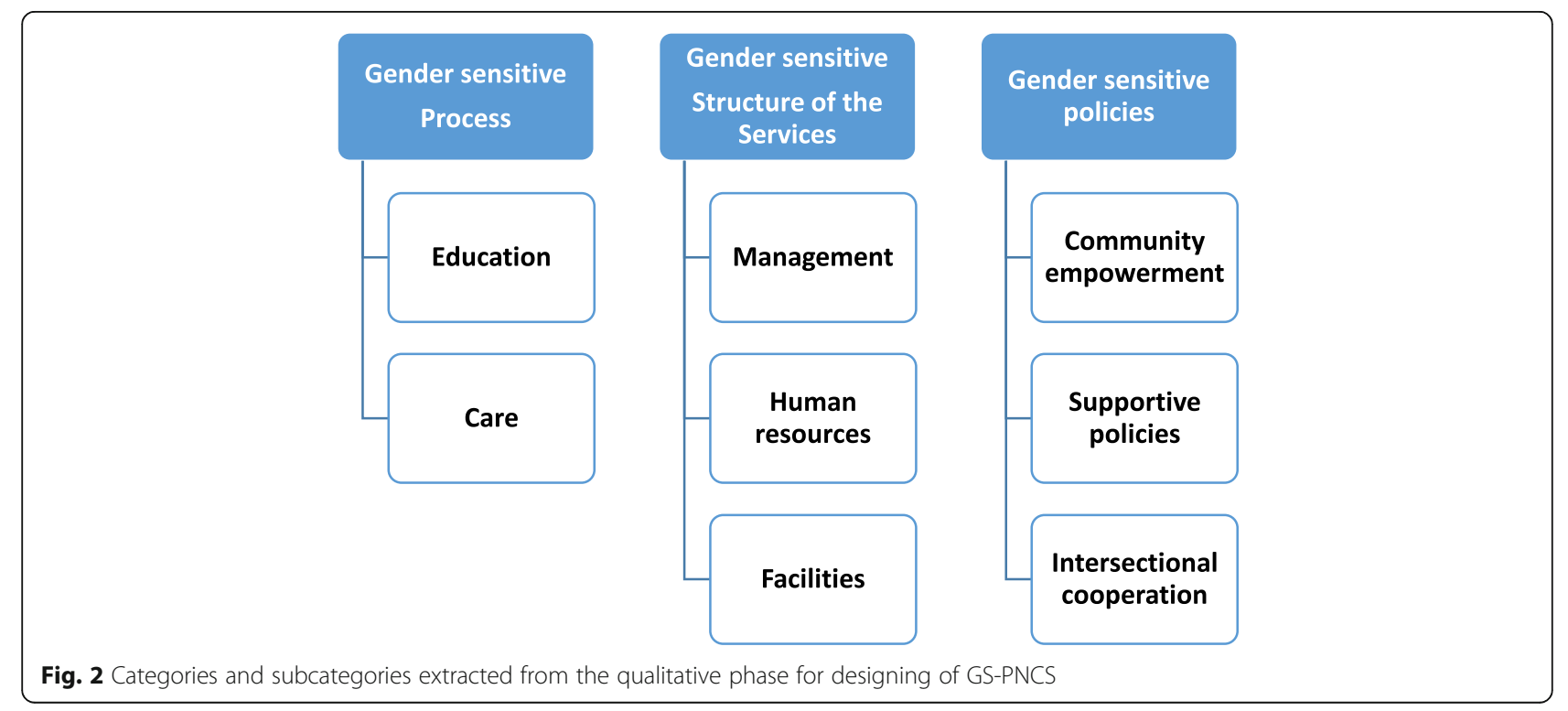


Table 1 Demographic characteristics of participants for factor analysis of GS-PNCS $(n=285)$

\begin{tabular}{llll}
\hline Characteristics & Category & Number & Percent \\
\hline Age & $20-30$ & 171 & 60.0 \\
& $31-40$ & 112 & 23.8 \\
Education & $>40$ & 42 & 16.2 \\
& Midwife (Bachelor) & 235 & 82.5 \\
& Midwife (Graduate Diploma) & 22 & 7.7 \\
& Midwife (Master) & 17 & 6.0 \\
Job experience & Health educator (Bachelor) & 9 & 3.1 \\
(Years) & 6-5 & 137 & 48.1 \\
& $11-15$ & 78 & 27.3 \\
& $16-25$ & 40 & 14.0 \\
& & 30 & 10.6 \\
\hline
\end{tabular}

confirmed by S-CVR and S-CVI, 0.92 and 0.98, respectively.

Then, the questionnaire with 57 items entered the stage of construct validity assessment. Figure 1 shows the process of designing and assessing psychometric assessment of GS-PNCS and the related changes of the questionnaire.

\section{Construct validity assessment}

The EFA method was used to assess the construct validity of GS-PNCS. Sample size for this section of the study was considered 5 sample for each items. Thus, for 57 items, 285 perinatal care providers recruited for the study (Table 1). The calculated KMO index was 0.822 and the Bartlett Sphericity test showed the correlation matrix 7715.23 with $P<0.0001$ which both showed sample adequacy for EFA.

Then, Commonalities calculations for items led to omission of an item "training medical students about health education of men and families" was omitted with commonality of $<0.3$.

Scree plot was used to predict the number of factors. The scree plot suggested 9 factors that became the default for factor analysis (Fig. 3)

Nine factors that explained $52.53 \%$ of cumulative variance of GS-PNCS were identified using the minimum eigenvalues of 1 . After Quartimax rotation and considering the factor loading of at least 0.4 , the items forming each factor were identified. Then, factor 8 was merged with factor 7 due to the fact that it contained only one item. 8 items with factor loading of 0.4 were omitted.

Table 2 reports the rotated factor matrix of the GSPNCS.

The factors 1 to 8 named as "Supportive policies to promote the gender sensitive services"; with 16 terms (explaining $14.18 \%$ of variance); "Structural reforms" with 6 items (explaining $6.57 \%$ of variance); "management considerations" with 6 items (explaining $5.83 \%$ of variance); "Women's rights promotion" with 5 items (explaining $4.99 \%$ of variance); "educational considerations" with 3

\section{Scree Plot}

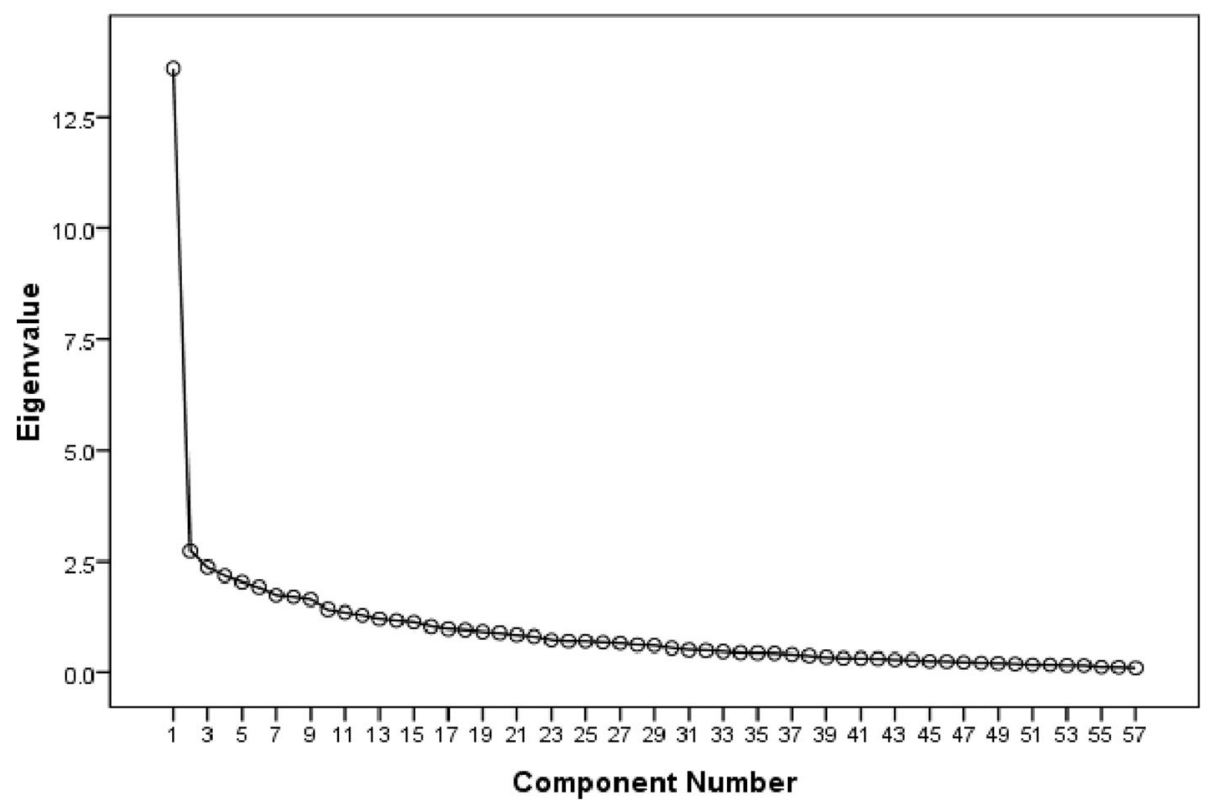

Fig. 3 Scree plot of the exploratory factor analysis of GS-PNCS 
Table 2 Rotated factor matrix of the GS-PNCS

\begin{tabular}{|c|c|c|c|c|c|c|c|c|c|}
\hline \multirow{2}{*}{\multicolumn{2}{|c|}{ Items }} & \multicolumn{8}{|c|}{ Factors } \\
\hline & & \multirow{2}{*}{$\begin{array}{l}1 \\
0.689\end{array}$} & \multirow[t]{2}{*}{2} & \multirow[t]{2}{*}{3} & \multirow[t]{2}{*}{4} & \multirow[t]{2}{*}{5} & \multirow[t]{2}{*}{6} & \multirow[t]{2}{*}{7} & \multirow[t]{2}{*}{8} \\
\hline 1 & Planning programs for enhancing male participation in perinatal care & & & & & & & & \\
\hline 2 & Education about preventing son preference in schools & 0.622 & & & & & & & \\
\hline 3 & Women's education about male participation in perinatal care & 0.617 & & & & & & & \\
\hline 4 & Planning to help single pregnant women & 0.573 & & & & & & & \\
\hline 5 & Educating men about problems related to unwanted pregnancy and abortion & 0.567 & & & & & & & \\
\hline 5 & Correcting women's misconceptions about male participation in perinatal care & 0.558 & & & & & & & \\
\hline 6 & Adolescents' education about the risks of pregnancy and abortion & 0.553 & & & & & & & \\
\hline 7 & Academic researches to eliminate son preference & 0.541 & & & & & & & \\
\hline 8 & $\begin{array}{l}\text { Gaining support from policy makers to promote the male participation in } \\
\text { perinatal care }\end{array}$ & 0.540 & & & & & & & \\
\hline 9 & $\begin{array}{l}\text { Develop community educational programs to promote male participation in } \\
\text { perinatal care }\end{array}$ & 0.526 & & & & & & & \\
\hline 10 & Promotion of male participation in perinatal care services through the media & 0.499 & & & & & & & \\
\hline \multicolumn{2}{|c|}{ Teaching "Parenting" in schools } & 0.493 & & & & & & & \\
\hline \multicolumn{2}{|r|}{ Considering male personnel to provide perinatal services to men } & 0.462 & & & & & & & \\
\hline \multicolumn{2}{|r|}{ Training male perinatal care providers to respond to men's problems } & 0.416 & & & & & & & \\
\hline \multicolumn{2}{|r|}{$\begin{array}{l}\text { Promoting male participation for making informed decision about method of } \\
\text { childbirth }\end{array}$} & 0.405 & & & & & & & \\
\hline \multicolumn{2}{|r|}{ Promoting men's awareness about methods of childbirth } & 0.402 & & & & & & & \\
\hline \multicolumn{2}{|r|}{ Devoting appropriate time for men's perinatal services } & & 0.693 & & & & & & \\
\hline \multicolumn{2}{|r|}{ Engaging volunteers to help in providing "parenting" services } & & 0.626 & & & & & & \\
\hline \multicolumn{2}{|r|}{$\begin{array}{l}\text { Employment of personnel to provide services to without any discrimination for } \\
\text { men or women }\end{array}$} & & 0.518 & & & & & & \\
\hline \multicolumn{2}{|r|}{$\begin{array}{l}\text { Providing services for diagnosis, treatment and follow up of male sexually } \\
\text { transmitted diseases }\end{array}$} & & 0.478 & & & & & & \\
\hline \multicolumn{2}{|r|}{ Providing counseling services for high-risk sexual behavior cases } & & 0.447 & & & & & & \\
\hline \multicolumn{2}{|r|}{ Providing sexual health counseling services by trained personnel } & & 0.409 & & & & & & \\
\hline \multicolumn{2}{|r|}{$\begin{array}{l}\text { Considering appropriate physical conditions for men's attendance in perinatal } \\
\text { services }\end{array}$} & & & 0.699 & & & & & \\
\hline \multicolumn{2}{|r|}{ Integrating prenatal health comments in premarital counseling programs } & & & 0.613 & & & & & \\
\hline \multicolumn{2}{|r|}{$\begin{array}{l}\text { Planning to correct misbeliefs of the providers about male participation } \\
\text { providers about male participation }\end{array}$} & & & 0.605 & & & & & \\
\hline \multicolumn{2}{|r|}{ Providing friendly care services for pregnant women with AIDS } & & & 0.554 & & & & & \\
\hline & mmending condom use to men with high-risk sexual behaviors & & & 0.489 & & & & & \\
\hline & $\begin{array}{l}\text { agement of workload for integrating paternal services in perinatal care } \\
\text { ces }\end{array}$ & & & 0.442 & & & & & \\
\hline & ation of reproductive health rights in universities & & & & 0.668 & & & & \\
\hline & $\begin{array}{l}\text { loping guidelines to protect rights of pregnant mothers in temporary } \\
\text { iage }\end{array}$ & & & & 0.552 & & & & \\
\hline & education about the risks of pregnancy and abortion in schools & & & & 0.491 & & & & \\
\hline & ing care providers about sexual health and rights of pregnant mothers & & & & 0.478 & & & & \\
\hline & loping guidelines to protect abused pregnant women & & & & 0.440 & & & & \\
\hline & iding effective counseling for post-abortion clients & & & & & 0.686 & & & \\
\hline & $\begin{array}{l}\text { iding premarital counseling about risks of adolescents' pregnancy for } \\
\text { age couples }\end{array}$ & & & & & 0.598 & & & \\
\hline & iding counseling to men about paternal role & & & & & 0.419 & & & \\
\hline & iding counseling for post-abortion clients & & & & & & 0.676 & & \\
\hline
\end{tabular}


Table 2 Rotated factor matrix of the GS-PNCS (Continued)

\begin{tabular}{|c|c|c|c|c|c|c|c|c|}
\hline \multirow[t]{2}{*}{ Items } & \multicolumn{8}{|c|}{ Factors } \\
\hline & $\overline{1}$ & 2 & 3 & 4 & 5 & 6 & 7 & 8 \\
\hline Providing special care and counseling before and after HIV testing of parents & & & & & & 0.691 & & \\
\hline Scheduling perinatal care visits for men & & & & & & 0.534 & & \\
\hline Evaluation of men's health in perinatal care services & & & & & & 0.423 & & \\
\hline Defining the Indices for Men's Participation for quality of care assessment & & & & & & 0.401 & & \\
\hline Increasing personnel's awareness about male participation & & & & & & & 0.551 & \\
\hline Paternal needs assessment using indicators & & & & & & & 0.530 & \\
\hline Counseling for solving paternal adaptation problems & & & & & & & 0.522 & \\
\hline $\begin{array}{l}\text { Monitoring the performance of the private sectors in promoting male } \\
\text { participation }\end{array}$ & & & & & & & 0.514 & \\
\hline Couple's training about methods of childbirth & & & & & & & 0.409 & \\
\hline $\begin{array}{l}\text { Educating couples about the effect of partner's sexual high-risk behaviors on } \\
\text { maternal and fetus health }\end{array}$ & & & & & & & & 0.516 \\
\hline Men's education about sexual health by educational booklets & & & & & & & & 0.490 \\
\hline Providing special sexual health education for pregnant adolescents & & & & & & & & 0.593 \\
\hline
\end{tabular}

items (explaining 4.78\% of variance); "care considerations" with 5 items (explaining 4.75\% of variance); "facilitating participation" with 5 items (Factor 7 and 8 totally explaining $7.74 \%$ of variance); "Sexual Health education" with 3 items (explaining $3.94 \%$ of variance); respectively.

Table 3 demonstrates the comparison of dimensions and sub-scales in qualitative and quantitative findings in the mix study of gender sensitive perinatal care services.

\section{Reliability}

To ensure reliability, both internal consistency and stability of GS-PNCS were assessed. Internal consistency of GS-PNCS was demonstrated by Cronbach $\alpha$ at 0.880 for whole instrument. To investigate stability, using the test-retest method, the correlation between the two testing occasions was computed. Correlation coefficient and intraclass correlation coefficient of the whole questionnaire were reported 0.980 and 0.973 , respectively. Table 4 Displays the results of questionnaire's reliability assessment. After confirming validity and reliability of the GS-PNCS, the questionnaire was finalized.

\section{Scoring procedure by GS-PNCS}

GS-PNCS was scored by a rating scale 1 to 3 . The range of scores for the whole questionnaire and its subscales are presented in Table 5. The total score of the GSPNCS and its subscales are calculated and presented as percentages. The range of scores is from $49(0 \%)$ to 147 (100\%) describing adequate gender sensitive PNC services to completely non adequate PNC services.

\section{Description of GS-PNC}

GS-PNCS is a valid scale with 49 items and 8 subscales that can be scored fron 49 to 147 (o to 100\%) and measures needs for a gender sensitive perinatal care service and its higher scores shows higher needs for the gender based PNCS.

Table 3 The comparison of dimensions and sub-scales in qualitative and quantitative findings in the mix study of gender sensitive perinatal care services

\begin{tabular}{lll}
\hline Dimensions & Categories (Qualitative study) & Sub-Scales (Factor Analysis) \\
\hline Gender Sensitive Policies & Supportive policies & Supportive policies to promote gender sensitive services \\
& Community empowerment & \\
Intersectional cooperation & Women's rights promotion \\
& Human resources & Structural reforms \\
Gender Sensitive Structure & Facilities & Facilitating male participation \\
& Management & Management considerations \\
& Care & Care considerations \\
& Education & Educational considerations \\
\hline
\end{tabular}


Table 4 Stability Coefficients and Interclass Correlation Coefficient of the GS-PNCS Subscales

\begin{tabular}{llll}
\hline Factors & $\begin{array}{l}\text { Cronbach's a } \\
\text { coefficient }\end{array}$ & $\begin{array}{l}\text { Interclass correlation } \\
\text { coefficient }\end{array}$ & $\begin{array}{l}\text { Test-retest Pearson } \\
\text { correlation coefficient }\end{array}$ \\
\hline $\begin{array}{l}\text { Supportive policies to promote gender } \\
\text { sensitive services }\end{array}$ & 0.905 & 0.817 & 0.895 \\
Women's rights promotion & 0.952 & 0.956 & 0.968 \\
Structural reforms & 0.780 & 0.927 & 0.927 \\
Faclitating male participation & 0.864 & 0.916 & 0.948 \\
Management considerations & 0.836 & 0.977 & 0.979 \\
Care considerations & 0.889 & 0.971 & 0.972 \\
Educational considerations & 0.896 & 0.973 & 0.980 \\
Sexual Health education & 0.889 & 0.991 & 0.999 \\
Total & 0.880 & 0.973 & 0.980 \\
\hline
\end{tabular}

Note. $\mathrm{PAQ}=$ Paternal Adaptation Questionnaire

Table 6 shows final version of the GS-PNCS with 49 items after Psychometric Properties Assessment.

\section{Discussion}

GS-PNCS is the first tool to assess gender sensitivity and appropriateness of PNCS for men and women. This valid and reliable tool is able to measure the responsiveness of perinatal services to the gender specific needs and so helps health care managers and planners to improve the quality of PNCS. Gender equity is mentioned as the characteristics of quality of maternal care services [31] and GS-PNCS is able to evaluate the adequacy of perinatal care responsiveness to clients' needs based on their gender roles.

GS-PNCS is a valid and important assessment tool to measure quality of PNCS regarding their gender sensitivity and so useful to improve the quality. A few tools are developed and applied to assess quality of PNCS [32-35], however, they are not able to measure the gender sensitivity of the services and moreover these tools were not assessed regarding some aspects of psychometric properties especially construct validity.
GS-PNCS was designed by inductive-deductive approach [19]. The qualitative part and the literature review demonstrated $\mathbf{8}$ dimentions for gender sensitive perinatal services including; gender sensitive care and educarional process; gendersensitive facilities, human resources and mangement; and community empowerment, sopurtive policies and intersectoral cooperation for the gender sensitive services. Then, the EFA indicated eigth factors which six of them were similar to the dimentions of the qualitative part. Finding showed PNCS need managerial, structural, facilities, educational and care procedures reforms for respoding to the specific needs of genders especially men which should be supported by the supportive policies $[36,37]$.

Face and content validity of GS-PNCS was confirmed qualitatively and quantitatively. Proper validity of a questionnaire usually refers to the vision of the target group about face validity, suitability, attractiveness, comprehensibility, culturally and socially appropriateness, logically sequence of the elements and the completeness of the instrument [19]. In qualitative face validity 8 items were deleted due to vague and duplication. In the quantitative face validity assessment,

Table 5 The Range of Scores and Subscales of the GS-PNCS

\begin{tabular}{lll}
\hline Factors/Subscales $^{\text {a }}$ & NO Items & Range of scores \\
\hline Supportive policies to promote the gender sensitive services & 16 & $16-48$ \\
Women's rights promotion & 5 & $5-15$ \\
Structural reforms & 6 & $6-18$ \\
Facilitating male participation & 5 & $5-15$ \\
management considerations & 6 & $6-18$ \\
care considerations & 5 & $5-15$ \\
educational considerations & 3 & $3-9$ \\
Sexual Health education & 3 & $3-9$ \\
Total & 49 & $49-147$
\end{tabular}

Note.GS-PNCS = Questionaaire to assess Gender Sensituve Pernatal Care Services; ${ }^{a}$ The score of total and the subscales are calculated and presented as percentage 
Table 6 The GS-PNCS at the End of Psychometric Properties Assessment

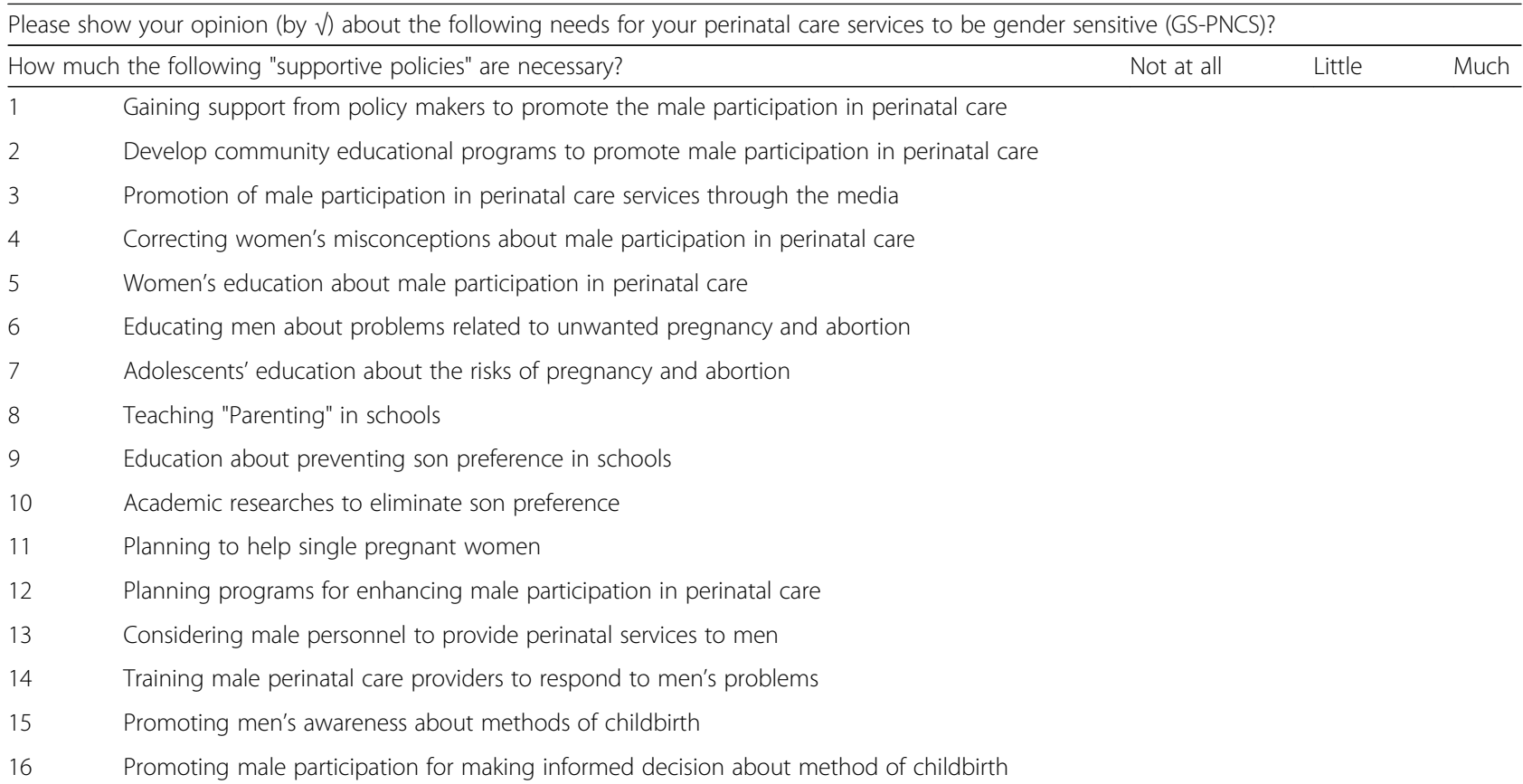

\section{How much the following strategies for "Women's rights promotion" are necessary?}

17 Developing guidelines to protect abused pregnant women

18 Developing guidelines to protect rights of pregnant mothers in temporary marriage

19 Training care providers about sexual health and rights of pregnant mothers

20 Girls' education about the risksof pregnancy and abortion in schools

21 Education of reproductive health rights in universities

How much the following "Structural reforms" are necessary for the perinatal care services?

22 Devoting appropriate time for men's perinatal services

23 Providing services for diagnosis, treatment and follow up of male sexually transmitted diseases

$24 \quad$ Providing counseling services for high-risk sexual behavior cases

$25 \quad$ Providing sexual health counseling services by trained personnel

26 Employment of personnel to provide services to without any discrimination for men or women

$27 \quad$ Engaging volunteers to help in providing "parenting" services.

How much the following strategies are necessary to "Facilitating male participation"?

28 Increasing personnel's awareness about male participation

29 Paternal needs assessment using indicators

$30 \quad$ Counseling for solving paternal adaptation problems

31 Monitoring the performance of the private sectors in promoting male participation

32 Couple's training about methods of childbirth

How much the following "management considerations" are necessary for gender sensitive Perinatal services?

33 Considering appropriate physical conditions for men's attendance in perinatal services

$34 \quad$ Integrating prenatal health comments in premarital counseling programs

35 Planning to correct misbeliefs of the providers about male participation

$36 \quad$ Providing friendly care services for pregnant women with AIDS

37 Recommending condom use to men with high-risk sexual behaviors 
Table 6 The GS-PNCS at the End of Psychometric Properties Assessment (Continued)

\begin{tabular}{|c|c|c|c|c|}
\hline \multicolumn{5}{|c|}{ 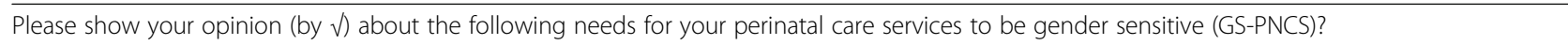 } \\
\hline \multicolumn{2}{|c|}{ How much the following "supportive policies" are necessary? } & \multirow[t]{2}{*}{ Not at all } & \multirow[t]{2}{*}{ Little } & \multirow[t]{2}{*}{ Much } \\
\hline 38 & Management of workload for integrating paternal services in perinatal care services & & & \\
\hline \multicolumn{5}{|c|}{$\begin{array}{l}\text { How much the following "care considerations" are necessary for gender sensitive perinatal } \\
\text { care services? }\end{array}$} \\
\hline 39 & Scheduling perinatal care visits for men & & & \\
\hline 40 & Evaluation of men's health in perinatal care services & & & \\
\hline 41 & Defining the Indices for Men's Participation for quality of care assessment & & & \\
\hline 42 & Providing care for post abortion patients & & & \\
\hline 43 & Providing special care and counseling before and after HIV testing of parents & & & \\
\hline \multicolumn{5}{|c|}{$\begin{array}{l}\text { How much the following "educational considerations" are necessary for gender sensitive } \\
\text { perinatal care services? }\end{array}$} \\
\hline 44 & Providing counseling to men about paternal role & & & \\
\hline 45 & Providing premarital counseling about risks of adolescents' pregnancy for teenage couples & & & \\
\hline 46 & Providing counseling for post-abortion clients & & & \\
\hline \multicolumn{5}{|c|}{$\begin{array}{l}\text { How much the following "sexual health education" are necessary in the perinatal } \\
\text { care services" }\end{array}$} \\
\hline 47 & $\begin{array}{l}\text { Educating couples about the effect of partner's sexual high-risk behaviors on maternal and } \\
\text { fetus health }\end{array}$ & & & \\
\hline 48 & Men's education about sexual health by educational booklets & & & \\
\hline 49 & Providing special sexual health education for pregnant adolescents & & & \\
\hline
\end{tabular}

impact score of all items were higher than 1.5 and shown to be acceptable. Content validity of GS-PNCS was also confirmed by S-CVR and S-CVI 0.92 and 0.98 , respectively. It shows that GS-PNCS has an appropriate sample of items for measuring gender sensitivity of the services [38].

Results of EFA showed "Supportive policies to promote the gender sensitive services"; with 16 terms explains highest variance and predictability for the sensitivity of the services "Structural reforms" and "management considerations" were second and third factors regarding their predictability for sensitivity of the services. Reproductive health policies and program formulation, has generally relied on data collected from women, while adequate policies and strategies are necessary to both men and women in their fertility control and STIs prevention care services [39]. Therefore, supportive policies are necessary as studies demonstrated that policy makers can increase implementation and effectiveness of an innovation such as making the services gender sensitive, by concentration on creating an environment that the providers perceive importance of the providing gender based services. In addition, managers should consider specific structural changes to increase positive perceptions and condition for implementation [40]. Gender roles are influenced by cultural characteristic of different communities. Besides, optimal patient care is affected by both scientific and social characteristics [41]. Therefore, community supportive policies and then structural changes by the gender sensitive management are necessary to improve Health services [42].
"Women's rights promotion" and "Facilitating male participation" were also extracted as the subscales of GS-PNCS. Studies shows that Reaching men to end gender-based violence and promote sexual and reproductive health rights of women are necessary [43]. Because of unequal gender-power relations, women are especially vulnerable but are often unable to negotiate changes in sexual behavior or to practice safe sex without the cooperation of their sexual partners. Therefore, men participation in reproductive health can span several themes. For example, men can be sources of transmission of STIs to women. When women get pregnant, their partners participate in making decisions which affects on their pregnancy such as seeking health care and place of delivery [44]. Therefore, special efforts should be made to emphasize men's shared responsibility and promote their active involvement in responsible sexual and reproductive behavior. It seems reasonable that if men are brought into a wide range of reproductive health services in such a way that they are supported as equal partners and responsible parents, as well as clients in their own right, better outcomes will be observed among both women and men [45].

Educational and care considerations based on gender specific needs and providing the sexual health education were other predictors of gender sensitivity of the services. The items were mainly related to providing care and education and sexual health services for men. Male involvement in perinatal care led to better birth 
outcomes. However, men are usually unavailable to attend perinatal programs because of work or feeling unwelcome at programs deemed "only for women" [46]. While they need care and education regarding their fatherhood adaptation process and roles during perinatal period [36]. Appropriate preparation for fatherhood has the potential to enhance maternal, child, and family health and even educational media such as e-health provide opportunities for men to prepare for fatherhood $[37,47,48]$.

Internal consistency and stabilityof GS-PNCS suggest high reliability of the questionnaire for assessment of gendersisivity of the questionnaire.

The study defined the concept of gender sensitivity of PNCS as a variable that can be measured by GS-PNCS containing 8 subscales that predict $53 \%$ of variance. Finding demonstrated gender sensitive PNCS needs supportive policies at the first steps and then requires the structural reforms by some management actions and considering some reforms in care and educational procedures and providing sexual health services. Meanwhile promotion of women right and male participation both in community and in the services are necessary. GS-PNCS provides the criteria for making PNCS gender sensitive and can be a base for the reform of the services.

GS-PNCS is developed and validated to show gaps in PNCS in the health care system of Shiraz. However, regarding to high validity and reliability of the questionnaire, it can be utilized not only in Shiraz but also for similar health care system of other provinces in Iran. Also it can be used to evaluate quality of PNCS in health systems of other countries. However, its validity and reliability is recommended to be assessed after translation to other languages.

GS-PNCS is a valid and reliable tool to show gaps in structure and procedures of PNCS and so helps to show priorities for the necessary interventions for planning a comprehensive gender based quality PNCS.

\section{Conclusion}

GS-PNCS is a valid (S-CVR $=0.92$ and S-CVI $=0.98)$ and reliable (Cronbach's $\alpha=0.880$ and the test-retest and Pearson Correlation $=0.947$ and ICC $=0.980$ ) questionnaire with 49 items to assess gender sensitivity of PNCS by a three level Likert scale. It include with 8 subscales including; "Supportive policies to promote the gender sensitive services"; "Structural reforms" "management considerations"; "Women's rights promotion"; "educational considerations"; "care considerations"; "Facilitating male participation"; "Sexual Health education" which predict $52.53 \%$ of variance.

\section{Abbreviations}

STIs: Sexually transmitted infections; PNCS: Perinatal care services; GS-

PNCS: Gender sensitivity of perinatal care services; S-CVR: Scale-level content validity ratio; S-CVI: Scale-level content validity index; CVR: Content Validity Ratio; CVI: Content Validity Index; ICC: Intra-class correlation; EFA: Exploratory factor analysis; KMO: Kaiser-Meyer-Alekin

\section{Acknowledgements}

Not Applicable.

\section{Authors' contributions}

MS, project development, data management, critical revision and editing, manuscript writing. FR, researcher, project development, data collection, concept and study design, manuscript, data analysis. SN, project development, data management, critical revision and editing, manuscript writing. AR, project development, data management, critical revision and editing. $\mathrm{NE}$, project development, data collection. $\mathrm{FZ}$, data analysis management. All authors have read and approved the final manuscript.

\section{Funding}

Not applicable.

\section{Availability of data and materials}

The datasets generated and/or analysed during the current study are not publicly available because the data are a part of an extensive research on reproductive gender sensitive reproductive health services including PNC, but are available from the corresponding author on reasonable request.

\section{Ethics approval and consent to participate}

The ethics committee affiliated with Shahid Beheshti University of Medical Sciences approved the study (Decree Number:

IR.SBMU.PHARMACY.REC.1398.224). Aims and processes of the study were explained to the providers. They were assured of the confidentiality of collected data and the possibility of withdrawal from the study at any time. Finally, participants signed a written informed consent before participating in this study.

\section{Consent for publication}

Not applicable.

\section{Competing interests}

The authors declare no conflict of interest.

\section{Author details}

${ }^{1}$ Midwifery and Reproductive Health Research Center, School of Nursing and Midwifery, Shahid Beheshti University of Medical Sciences, Tehran, Iran. ${ }^{2}$ Department of Midwifery and Reproductive Health, School of Nursing and Midwifery, Shahid Beheshti University of Medical Sciences, Tehran, Iran. ${ }^{3}$ Department of Midwifery, Chalous Branch, Islamic Azad University, 17 Shahrivar Street, opposite the mosque of Imam Hussain (AS), Chalous 4661961367, Iran. ${ }^{4}$ Department of Public Health, Faculty of Health, Shahid Beheshti University of Medical Sciences, Tehran, Iran. ${ }^{5}$ Department of Midwifery, School of Nursing and Midwifery, Qom University of Medical Sciences, Qom, Iran. ${ }^{6}$ Department of Biostatistics, Faculty of Paramedicine, Shahid Beheshti University of Medical Sciences, Tehran, Iran.

Received: 15 March 2020 Accepted: 13 May 2020

Published online: 06 July 2020

\section{References}

1. Borchers AT, Gershwin ME. Sociological differences between women and men: implications for autoimmunity. Autoimmun Rev. 2012;11:A413-21.

2. Stroumsa D. The state of transgender health care: policy, law, and medical frameworks. Am J Public Health. 2014;104:e31-8.

3. Celik H, Lagro-Janssen TA, Widdershoven GG, Abma TA. Bringing gender sensitivity into healthcare practice: a systematic review. Patient Educ Couns. 2011:84:143-9.

4. World Health Organization. Global Strategy for Women's, Children's and Adolescents' Health 2016-2030. Geneva: every woman every child, WHO; 2015. Available from: http://www.who.int/life-course/publications/globalstrategy-2016-2030/en/. .

5. Hayes BC, Prior P, Campling J. Gender and health care in the UK: exploring the stereotypes. Macmillan International Higher Education; 2017. 
6. World Health Organization. Gender and Road Traffic Injuries. Geneva, Switzerland: WHO, Department of Gender and Women's Health; 2002. Available from: http://apps.who.int/iris/bitstream/10665/68887/1/a85576.pdf. Accessed 25 Nov 2018

7. Risberg G, Johansson EE, Westman G, Hamberg K. Attitudes toward and experiences of gender issues among physician teachers: a survey study conducted at a university teaching hospital in Sweden. BMC Med Educ. 2008:8:10.

8. Glenn EN. Social constructions of mothering: a thematic overview Mothering: Routledge; 2016. p. 1-29.

9. Kabagenyi A, Jennings L, Reid A, Nalwadda G, Ntozi J, Atuyambe L. Barriers to male involvement in contraceptive uptake and reproductive health services: a qualitative study of men and women's perceptions in two rural districts in Uganda. Reprod Health. 2014;11:21.

10. Cook RJ, Dickens BM, Fathalla MF. Reproductive health and human rights: integrating medicine, ethics, and law. New York: Clarendon Press. OXFORD; 2003

11. Davis J, Luchters S, Holmes W. Men and maternal and newborn health: benefits, harms, challenges and potential strategies for engaging men. Melbourne, Australia: Compass: Women's and Children's Health Knowledge Hub; 2012.

12. U N Women. The Beijing declaration and platform for action turns 20. New York: UN Women; 2015.

13. Morgan R, George A, Ssali S, Hawkins K, Molyneux S, Theobald S. How to do (or not to do) ... gender analysis in health systems research. Health Policy Plan. 2016;31:1069-78.

14. Joint United Nations Programme on HIV/AIDS (UNAIDS). Sexual Health Education Does Lead to Safer Sexual Behaviour. Press Release; 1997;22.

15. Simbar M, Nahidi F, Ramezani-Tehrani F, Akbarzadeh A. Educational needs assessment for men's participation in perinatal care. East Mediterr Health J. 2011;17:689-96.

16. Orji EO, Adegbenro CO, Moses OO, Amos OT, Olanrenwaju OA. Men's involvement in safe motherhood. J Turkish-Germany Gynecol Assoc. 2007;8:240-6.

17. Newman C. Gender sensitivity assessment. Tools for $\mathrm{RH}$ service providers and managers; 2003

18. Waltz J. Algorithm to determine wheel and brake cooling. Google Patents; 2012

19. Creswell JW, Creswell JD. Research design: qualitative, quantitative, and mixed methods approaches. London: Sage publications; 2017.

20. Graneheim UH, Lundman B. Qualitative content analysis in nursing research: concepts, procedures and measures to achieve trustworthiness. Nurse Educ Today. 2004;24:105-12.

21. Lincoln YS, Guba EG. The roots of fourth generation evaluation. In: Alkin MC, editor. Evaluation roots: tracing Theorists' views and influences. London: Sage publication; 2004. p. 225-41.

22. Hajizadeh E, Asghari M. Statistical methods and analyses in health and biosciences a research methodological approach. Tehran. 2011;395.

23. Polit-O'Hara D, Beck CT. Essentials of nursing research: methods, appraisal, and utilization. 6th ed. Philadelphia: Lippincott Williams \& Wilkins; 2006.

24. Lawshe $\mathrm{CH}$. A quantitative approach to content validity. Pers Psychol. 1975; 28:563-75.

25. Waltz CF, Strickland OL, Lenz ER. Measurement in nursing and health research. London, England: Springer Publishing Company; 2010.

26. Plichta SB, Kelvin EA, Munro BH. Munro's statistical methods for health care research. Philadelphia: Wolters Kluwer Health/Lippincott Williams \& Wilkins; 2013.

27. Harman HH. Modern factor analysis. 2nd ed. Chicago: University of Chicago Press; 1976.

28. Schneider Z Nursing research: methods, critical appraisal and utilisation. 2nd ed. Sydney Mosby; 2003.

29. Litwin MS, Fink A. How to measure survey reliability and validity, vol. 7. London: Sage publication; 1995.

30. Baumgartner TA, Chung H. Confidence limits for intraclass reliability coefficients. Meas Phys Educ Exerc Sci. 2001;5:179-88.

31. World Health Organization. Standards for improving quality of maternal and newborn care in health facilities. Geneva: WHO; 2016.

32. Wendy Sword R, Maureen Heaman R, Ann SR. Psychometric testing of the French language quality of prenatal care questionnaire. J Nurs Meas. 2015;23:436.
33. Azarabadie S, Aghlmand S. The Real Quality of Maternity Care in Iran Hospitals: A Quality Assessment Study.IIOAB J. 2016;7:611-617.

34. Changaee F, Simbar M, Irajpour A, Akbari S. Quality assessment of peripartum care. Iran Red Crescent Med J. 2014;16:e9069.

35. Simbar M, Nahidi F, Dolatian M, Akbarzadeh A. Assessment of quality of prenatal care in Shahid Beheshti medical Science University centers. Int J Health Care Qual Assur. 2012;25:166-76.

36. Eskandari N, Simbar M, Vedadhir A, Baghestani AR. Paternal adaptation in first-time fathers: a phenomenological study. J Reprod Infant Psychol. 2017; 35:53-64.

37. Simbar M, Nahidi F, Ramezankhani A. Fathers' educational needs for perinatal Care in Urban Iran: a qualitative approach. J Biosoc Sci. 2010;42: 633-41.

38. Polit DF, Beck CT. Nursing research: principles and methods. 7th ed. Philadelphia: Lippincott Williams \& Wilkins; 2004.

39. Bankole A, Singh S. Couples' fertility and contraceptive decision-making in developing countries: hearing the man's voice. Int Fam Plan Perspect. 1998 24:15-24.

40. Jacobs SR, Weiner BJ, Reeve BB, Hofmann DA, Christian M, Weinberger M. Determining the predictors of innovation implementation in healthcare: a quantitative analysis of implementation effectiveness. BMC Health Serv Res. 2015;15:6.

41. Grol R, Wensing M, Eccles M, Davis D. Improving patient care: the implementation of change in health care. New Jersey: John Wiley \& Sons; 2013.

42. Marston C, Hinton R, Kean S, Baral S, Ahuja A, Costello A, et al. Community participation for transformative action on women's, children's and adolescents' health. Bull World Health Organ. 2016;94:376.

43. Peacock D, Levack A. The men as partners program in South Africa: reaching men to end gender-based violence and promote sexual and reproductive health. Int J Mens Health. 2004;3:173.

44. Osamor PE, Grady C. Zika virus: promoting male involvement in the health of Women and families. PLoS Negl Trop Dis. 2016;10:e0005127.

45. McIntosh CA, Finkle JL. The Cairo conference on population and development: a new paradigm? Popul Dev Rev. 1995;21:223-60. https://doi. org/10.2307/2137493.

46. Mackert M, Guadagno M, Donovan E, Whitten P. Including men in prenatal health: the potential of e-health to improve birth outcomes. Telemed $E$ Health. 2015;21:207-12.

47. Gage JD, Kirk R. First-time fathers: perceptions of preparedness for fatherhood. Canadian Journal of Nursing Research Archive. 2016;34.

48. Kato-Wallace J, Barker G, Eads M, Levtov R. Global pathways to men's caregiving: mixed methods findings from the international men and gender equality survey and the men who care study. Glob Pub Health. 2014;9:706-22.

\section{Publisher's Note}

Springer Nature remains neutral with regard to jurisdictional claims in published maps and institutional affiliations.

Ready to submit your research? Choose BMC and benefit from:

- fast, convenient online submission

- thorough peer review by experienced researchers in your field

- rapid publication on acceptance

- support for research data, including large and complex data types

- gold Open Access which fosters wider collaboration and increased citations

- maximum visibility for your research: over $100 \mathrm{M}$ website views per year

At BMC, research is always in progress.

Learn more biomedcentral.com/submissions 